\title{
LA DIGNIDAD DEL HOMBRE
}

\author{
Joaquín García-Huidobro* \\ Profesor de Derecho \\ Universidad de Los Andes
}

En la segunda mitad del siglo $X X$ se ha hablado y escrito mucho sobre la dignidad humana ${ }^{1}$. Cabe esperar que en las próximas décadas no se interrumpa esa saludable costumbre, aunque más de uno pueda preguntarse: ¿por qué? No sólo por qué conviene seguir hablando de la dignidad humana, sino algo más radical: ¿ por qué podemos decir que el hombre tiene una dignidad? ¿No será sólo una locución que tiene por objeto mantener a los hombres convencidos de su superioridad respecto del resto de los seres?, ¿o quizá se trate de una rémora proveniente del antiguo pensamiento europeo, que constituye un límite, una traba, para el desenvolvimiento de los sistemas sociales? La cuestión no es ociosa, especialmente en una época en la que muchos plantean la necesidad de disolver al sujeto, ya sea en el lenguaje, en las estructuras o en los sistemas. $Y$, si se piensa bien, desde diversas perspectivas cabe observar al hombre sin distinguirlo de los demás cuerpos. La física de Newton funciona igual sea que caigan manzanas o personas desde las alturas. Otra tanto cabe decir de muchas otras ciencias. La cuestión ha sido tratada por muchos autores en los últimos años y, paradójicamente, los ha llevado a terrenos metafísicos en los que no se sienten muy cómodos.

\section{Las Declaraciones de derechos y la dignidad humana}

Puesto que para tratar de algo es necesario tener un punto de partida, y ya que estamos en una Escuela de Derecho, podríamos preguntarnos qué dicen los textos juridicos acerca de la dignidad humana. No significa esto que la dignidad humana sea un producto de los textos jurídicos: ellos mismos nos dicen que no es así. Y para ahorrarnos trabajo, empecemos por el siglo XVIII, época de surgimiento del constitucionalismo en el cual aún vivimos. Comencemos por un texto venerable dentro de la tradición constitucionalista, la Declaración de derechos de Virginia, aprobada el 12 de julio de 1776 .

Lo primero que llama la atención, ya en el preámbulo, es la autoestima que tienen los declarantes y su conciencia de estar haciendo algo muy importante. Así, dicen que se trata de "una declaración de derechos hecha por los representantes del buen pueblo de Virginia, reunidos en asamblea plenaria y libre; derechos que pertenecen a

* Este trabajo fue realizado como parte de un proyecto que patrocinó la Dirección de Investigación de la Universidad de Valparaiso

1 Un ejemplo en nuestro medio es: AA.VV.. La dignidad de la persona. XXV Jornadas de Derecho Público. Edeval. Valparaíso. 1995 ( 3 vols). Para nuestra materia interesa especialmente el texto de P. Serna, "La dignidad de la persona como principio del Derecho Público" (vol. 1, 363-386). 
ellos y a su posteridad, como la base y el fundamento del gobierno". En estas pocas palabras se resume el contenido de todo el texto y buena parte de la filosofía política moderna. El pueblo de Virginia no redacta y proclama por sí mismo este documento. Para eso tiene sus representantes. Estos se reúnen en condiciones adecuadas y proclaman que la base última de legitimidad de un gobierno son los derechos individuales. Más adelante se explicará que los derechos de los hombres no son concesión graciosa de los gobernantes, sino que les pertenecen por naturaleza; que esos derechos no son renunciables y que el gobernante no es más que un servidor de ese pueblo, que tiene por misión el promover su respeto. Y si no cumple, podrá ser depuesto. Asi de simple.

La Declaración de derechos de Virginia, no nos da una respuesta última a la pregunta por el valor del hombre, pero nos muestra algo muy interesante: cómo actúan y qué dicen unos hombres que están absolutamente convencidos de su valer. También nos hace ver que esa dignidad tiene que ver, al menos en ese medio cultural, con la idea de derechos y, más específicamente, con la circunstancia de que estos derechos son innatos y no adquiridos. Es decir, al leer este texto, da la impresión de que la dignidad es algo constitutivo del hombre, y no una propiedad que le adviene con posterioridad a su nacimiento.

Pero, aunque se trate del buen pueblo de Virginia, es posible que algunos de sus habitantes cometan delitos. $\mathrm{O}$ al menos que así lo parezca. Para tales casos, se establecen normas para asegurarle un juicio justo y la debida defensa ${ }^{2}$. Además, se prohiben los castigos excesivos, y aquellos que puedan ser calificados de crueles o inusitados ${ }^{3}$. Todo esto nos muestra que aún el delincuente merece un trato determinado, un mínimo que muchos estarán tentados a considerar excesivo. $Y$ esto no sería comprensible si el hombre que delinque perdiera toda su valía. Es decir, parece que estamos en presencia de una propiedad que nunca puede perderse del todo. Además, junto con proclamarse la libertad en materia religiosa, se insta a los hombres a que, por encima de sus diferencias, mantengan entre ellos un comportamiento fraternal. Es decir, los hombres de los que alli se habla deben cumplir también con ciertos deberes. Son hombres de los que se espera responsabilidad. Lo dice claramente, hacia el final de la declaración, la sección 15, al señalar "que ni el gobierno libre, ni las bendiciones de la libertad, pueden ser preservados por un pueblo, sin una firme adhesión a la justicia, la moderación, la templanza, la frugalidad y la virtud, y sin un frecuente retorno a los principios fundamentales". Este texto muestra muchas cosas, entre ellas que los hombres son seres que pueden sujetar sus pasiones al imperio de la razón. Son capaces de virtud. Al mismo tiempo, se da a entender que, junto con los derechos de los que se hablaba al principio, en la base de la vida social se hallan ciertos principios fundamentales que nunca hay que perder de vista. El mantener la libertad es una tarea exigente.

El siguiente texto es aún más conocido: la Declaración de los derechos del hombre y del ciudadano, de 1789. Aunque presenta diferencias con la Declaración de derechos de Virginia, cabe encontrar algunos rasgos comunes en la respuesta que dan a la pregunta por el valor del hombre. En ella también se habla de ciertos derechos, a los que se califica como "naturales, inalienables y sagrados". Estos derechos constituyen

Secc. 8.

3 Secc. 9. 
asimismo la piedra de toque para juzgar la legitimidad de los gobiernos, y su menosprecio lleva consigo la mayor de las desgracias para una sociedad. El fin de toda asociación política, en consecuencia, es la conservación de esos derechos ${ }^{4}$.

Asimismo, se destaca no sólo que los hombres son libres, sino también iguales ${ }^{5}$. Esta afirmación, aunque dista de ser original, es de gran importancia. Quien señala que los hombres son iguales, no obstante sus notorias diferencias intelectuales y corporales, está diciendo que esa igualdad no deriva de lo que se tiene, del reconocimiento social o del poder. En esto los hombres son, guste o no, muy distintos. La igualdad reside en algo más profundo, que, por tanto, no puede perderse por muy adversa que sea la suerte que sufra cada uno.

Por otra parte, se reconoce un papel decisivo a la voluntad individual y a su autonomía. Los declarantes reconocen que existe un ámbito privado, en el que el sujeto se conduce a sí mismo como mejor le parece y administra lo suyo. Allí la ley sólo puede entrar por motivos muy calificados ${ }^{6}$. Es más, la elaboración misma de la ley es algo que depende de los ciudadanos? ${ }^{7}$ por eso se piensa que al obedecer a la ley los hombres se obedecen a sí mismos.

El sentido de la fuerza pública, entonces, no es más que la garantía de los derechos del hombre ${ }^{8}$. Ella, como toda potestad, tiene una función de servicio. Los ciudadanos, que contribuyen al financiamiento de los órganos de gobierno, tienen el derecho de fiscalizarlos ${ }^{9}$ y los funcionarios están obligados a rendir cuentas de su administración $^{10}$.

Muchas críticas se podrán hacer a las deficiencias filosóficas que pueda tener esta Declaración, y más aún a los sucesos históricos que acompañaron su aplicación práctica. Pero, al igual que en la Declaración de derechos de Virginia, vemos aquí la idea de un hombre que es el protagonista de la vida social, a cuyo servicio está hasta el más encumbrado de los poderes públicos. $Y$ este valor se le reconoce al hombre no por el lugar que ocupe en la vida social, sino en virtud de lo que es.

El texto de derechos humanos más famoso del siglo XX es la Declaración Universal, de 1948. Como su nombre lo indica, no se trata de un texto redactado y circunscrito a un solo país. Sus redactores pertenecian a corrientes filosóficas muy diferentes y provenían de diversas partes del mundo. Además, casi todas las naciones han adherido a ella. Como se ha destacado en muchas oportunidades, la diversidad de origen y cultura de sus redactores explica el que se hayan omitido aquellas cuestiones filosóficas y de fundamentación que habrían hecho imposible llegar a un acuerdo práctico. Sin embar-

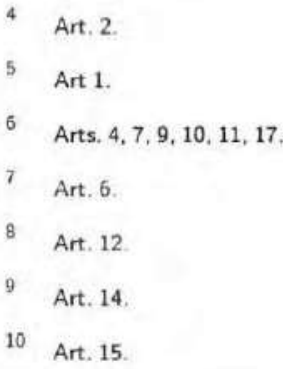


go, no sólo no está ausente de ella la dignidad del hombre, sino que constituye el pilar mismo de todo el texto. De su respeto depende, según se dice en el Preámbulo la existencia misma de la libertad, la justicia y la paz en el mundo.

La dignidad humana se presenta allí como "intrínseca", es decir, no deriva de circunstancias añadidas desde el exterior, sino que pertenece a los seres humanos por el solo hecho de ser tales. Reforzando esta idea, se alude a la existencia de ciertos derechos iguales e inalienables, de los que participan todos los miembros de la familia humana ${ }^{11}$, expresiones estas que refuerzan la idea de una naturaleza común a todos los hombres y de ciertos derechos que, en la línea del constitucionalismo clásico, se entienden como propios del hombre. Es decir, se nace con ellos ${ }^{12}$.

La común dignidad y derechos tiene múltiples expresiones. El carácter de persona ante el derecho debe ser reconocido a todos los seres humanos, dondequiera que se encuentren ${ }^{13}$; se prohibe absolutamente la esclavitud ${ }^{14}$ y otras situaciones degradantes y se le reconocen a los hombres los derechos civiles y políticos, entre los que ciertamente se halla el de participar en el gobierno ${ }^{15}$. Asimismo, el hombre no es visto de manera aislada, sino que se reconoce su vinculación para con los demás, y la posibilidad de formar diversas agrupaciones intermedias ${ }^{16}$. Esta apertura a los demás es no sólo una exigencia de justicia, sino condición del propio desarrollo personal ${ }^{17}$. Asimismo, se dice que la familia tiene el carácter de elemento natural y fundamental de la sociedad ${ }^{18}$. Una sociedad bien fundada, por tanto, no estará compuesta de meros individuos aislados, sino de personas que se integran a ella desde instancias intermedias, entre los cuales la familia tiene una importancia peculiar.

De la lectura de estos textos podemos observar que nos hallamos frente a un sujeto, el hombre, que debe ser tratado de modo muy diferente a como se tratan las cosas. Se le reconoce racionalidad y libertad y se espera de él un comportamiento justo respecto de sus semejantes. En el caso de las Declaraciones del siglo XVIII, además. existe un reconocimiento explícito de la trascendencia. La determinación y respeto de sus derechos, asimismo, no queda entregada a la voluntad de gobernantes o de grupos sociales, aunque sean mayoritarios, sino que se imponen como límites al poder, es decir, constituyen un terreno que no está sujeto a disposición. En el caso de la Declaración Americana de derechos del hombre, se agrega además todo un capítulo destinado a enunciar los deberes de los hombres. Es decir, se ponen de manifiesto las consecuencias prácticas de su responsabilidad.

\footnotetext{
11 Declaración Universal de Derechos Humanos (DUDH), Preámbulo.

12 DUDH, Art. 1.

13 DUDH, Art. 6.

14 DUDH, Art. 4.

15 DUDH, Art. 21.

16 DUDH. Art. 20.

17 DUDH, Art. 29.1.

18 DUDH. Art. 16.3.
} 
Ideas semejantes, y aún más desarrolladas, se encuentran en los diversos textos constitucionales contemporáneos. Ellos no son más que un esfuerzo por expresar lo que señala la Ley Fundamental alemana en el más famoso de sus artículos: "la dignidad humana es inviolable" ${ }^{19}$. Si se observa la arquitectura misma de estas constituciones se verá que todas ellas, antes de comenzar a señalar y dividir los poderes del Estado y sus atribuciones, dedican una buena parte a tratar de materias directamente vinculadas con la dignidad del hombre y sus derechos ${ }^{20}$. Con esto, entre otras cosas, se indica la razón de ser y la base de la organización estatal.

\section{Una noción universal}

Los textos que hemos comentado muestran que sus redactores reconocen que la dignidad es una nota o valor que se aplica a todos los seres humanos, sin distinción. En esto, como lo observa Charles Taylor, hay una diferencia respecto de otros conceptos, como el de honor, que por definición no corresponde a los hombres en un mismo grado $^{21}$. Además, hay actos cuya sola realización implica la deshonra de quien los practican. En cambio, tratándose de la dignidad parece justificado preguntarnos si ella puede perderse, $\mathrm{o}$ al menos aumentar o disminuir.

La respuesta a la pregunta acerca de si cabe perder la dignidad puede abordarse en dos planos. En el primero, ontológico, esta respuesta es negativa. Los hombres, por el solo hecho de serlo tienen una dignidad, son dignos, y no pueden perderla sin dejar de ser hombres. En cambio, hay un segundo sentido, de carácter existencial, en el cual cabe hacer algunos matices importantes. De partida, todos reconocemos que hay ciertos actos, como la trata de blancas o la explotación de menores, que son indignos del hombre. Quienes los realizan no se están comportando como personas, no actúan conforme a su dignidad. Pero eso no significa que la pierdan, sino más bien que sufren una contradicción entre lo que son, o están llamados a ser, y los actos que realizan. Algo parecido al caso de un hijo que no responde a la confianza de su padre, que lo defrauda: su comportamiento no es el propio de un hijo, pero no deja de serlo. En semejante sentido hablamos de personas que no son dignos del cargo que ocupan. Aquí falta la dignidad para (algo) pero no se ha perdido la dignidad de (ser hombre). Es decir, no existe la indignidad absoluta. Aún en los seres humanos más degradados se mantiene esa dignidad primera que corresponde a los hombres por el solo hecho de serlo. Hay un segundo sentido existencial en el cual la dignidad se ve afectada. Nos referimos a aquellas personas que sufren humillaciones, maltratos o vejaciones. En este caso no se trata de que alguien haga una cosa indigna del hombre sino de que se le haga algo que no corresponde a su dignidad humana. En estos casos, la dignidad de la víctima no sólo no disminuye sino que en muchos casos se pone de manifiesto de modo palpable. Los esqueletos vivientes que encontraron los aliados al entrar en Auschwitz muestran, en su indigencia total, la dignidad humana de un modo particularmente elocuente. Por eso se dice que esos actos indignos rebajan a los autores más que a las víctimas. Es el viejo

19

GG Art. 1.1.

20

Cfr. GG Arts. 1-19; CPR 1980 Arts. 1-23.

21

Cfr. Ch. Taylor, Ética de la autenticidad. Paidós. Barcelona. 1993, 79-81 
pensamiento socrático: "es preferible sufrir una injusticia a cometerla" ${ }^{22}$. No es casual que precisamente después de haber vivido diversas experiencias totalitarias los hombres hayan sentido la necesidad de proclamar nuevamente declaraciones de derechos ${ }^{23}$.

Consecuencia de la dignidad personal es que el hombre nunca debe ser utilizado simplemente como un medio para el logro de otros objetivos, porque en ese caso se lo estaría tratando no como una persona sino como una cosa, como un simple instrumento. Naturalmente la noción de dignidad personal trae no pocas dificultades en la práctica jurídica y política. Quien esté dispuesto a reconocerla y respetarla tendrá que reconocer necesariamente que su actuación y su poder están limitados por ese dato previo. Era precisamente lo que intentaban señalar los autores de las declaraciones clásicas al aludir a la existencia de ciertos derechos innatos, que no se tienen por concesión estatal sino que más bien constituyen un límite a la acción de los gobiernos. Los derechos que señalan esas declaraciones, y muchos otros, puede decirse que son la expresión jurídica y política de la dignidad humana. En este sentido, la dignidad no es un derecho, sino más que un derecho: es el fundamento mismo de que tengamos derechos. Los derechos del hombre no son más que aspectos en los cuales la dignidad debe ser protegida. Si los derechos fundamentales son expresión de la dignidad, y la dignidad pertenece a cada persona en particular, bien puede decirse que cualquier preocupación por los derechos humanos que olvide a las personas reales y concretas es un contrasentido. Esta observación es elemental, pero muchas veces se ha perdido de vista. Quizá allí resida, en parte, la explicación de por qué las declaraciones de derechos clásicas hayan sido interpretadas y aplicadas en ciertos casos de un modo que parece contradecir la letra y el espíritu de lo que señalaban. Y este mal también puede afectar $-y$ ha afectado- la interpretación y aplicación de nuestras declaraciones contemporáneas. no (everyone) tiene derecho, en todas partes, al reconocimiento de su personalidad jurídica". Este artículo constituye la piedra angular de la Declaración, al establecer la equivalencia entre ser individuo de la especie humana y ser persona. Desde el punto de vista político, esta afirmación envuelve el que nadie tiene la facultad de determinar qué seres humanos serán reconocidos como personas. El arrogarse un poder semejante significaría una velada forma de totalitarismo. La importancia histórica de este principio de la personalidad jurídica es evidente, p. ej. a propósito de la esclavitud. No sería válido utilizar a su respecto razones como "si Ud. no quiere tener un esclavo no lo tenga", o "la prohibición de la esclavitud significa imponer las convicciones religiosas de un grupo al resto de la sociedad". En forma análoga, también la legalización del aborto envuelve una lesión de esta ecuación entre la pertenencia de un individuo a la especie humana y el carácter de persona, en cuanto la ley establece que hay un grupo de seres humanos a los que se les niegan algunos derechos propios de la persona, como por ejemplo el del debido proceso. En efecto, el aborto supone la aplicación de la pena capital sin atender a los criterios que se establecen para un proceso justo (cfr. A.-C. Pereira et alii, Temas de Derecho Constitucional Español. Follas Novas. Santiago de Compostela. 1996). Si todos los derechos fundamentales son expresión de la dignidad humana, el derecho a la personalidad jurídica es la primera de sus manifestaciones. 